\title{
Italian Trade Specialization: Persistence and Change in Regional Agri-Food Production
}

M. Platania, P. Rapisarda, M. Rizzo

University of Catania, Italy

\begin{abstract}
The Italian agri-food sector has traditionally been one of the strongest in the national socio-economic system. In the last ten years, commercial exchange trends have shown growing openness towards foreign countries and in particular to European Union (EU) countries. Both the primary sector and food industry are strongly influenced by their territorial location so much so that several authors have highlighted territorial specialisation and its effects on that territory's features also considering the contribution of the Italian Regions. The following work will analyse the patterns of agri-food specialisation in the Italian Regions. In particular, the Lafay Index will be used to evaluate competitive advantage at a Regional level.
\end{abstract}

\section{Keywords}

Agricultural trade. Lafay Index. Comparative advantage. Regional specialization.

Platania, M., Rapisarda, P. and Rizzo, M. (2015) "Italian Trade Specialization: Persistence and Change in Regional Agri-Food Production ", AGRIS on-line Papers in Economics and Informatics, Vol. 7, No. 4, pp. 101 - 109, ISSN 1804-1930.

\section{Introduction}

Generally, international commerce and exports in particular are among the main motors of a nation's economic growth. This is even more true in Italy where the specialisation model has strongly correlated economic performance in recent years with foreign trade. The debate on the Italian specialisation model has highlighted several characteristics which make it anomalous among the other industrialised nations: strong specialisation in the 'traditional' sector of intense unqualified work, fairly strong in light low-technology mechanical engineering and significant under-specialisation in high-technology sectors (Platania, 2012). These characteristics could according to some observers put the Italian economy in direct competition with emerging nations.

Without its own raw materials, Italy has always had to procure natural resources and this strongly characterises its foreign trade. Furthermore, the foreign component of demand has contributed to sustaining the economy compared with fairly weak internal demand. These characteristics are understandable by considering Italy's international trade from 1991 to 2012 (figure 1). Despite import and export trade flows being substantially static, the overall trend has been toward growth over the 20 years except for the sharp downturn due to the recession in 2009. That growth has more than tripled and after 8 years of deficit, the trade balance in 2012 had returned to being surplus.

This is even more noticeable by looking at the trade balance which accounts for the overall level of trade exchange (the normalised surplus is given by the ratio percentage between the current trade surplus and the export and import total: it varies between -100 for a country which imports everything to +100 for a country which entirely exports and if imports and exports balance then the normalised surplus is 0 ). The normalized trade balance curve trend highlights Italy's worsening trade performance as starting in 1997, several years before the economic crisis.

Getting back to a general analysis, the performance trend is influenced by various production sectors each of which contributes variously to the overall trade balance. Among the main contributors, apart from manufacturing - and in particular Machine tools, one of the strong points in International Specialisation of the Italian economy - is Agri-Food both economically and for its effects on the territory making it one of the most important sectors in the Italian trade balance. Italy and its regions possess a rich and varied agricultural and food heritage, due to its wealth of natural resources 


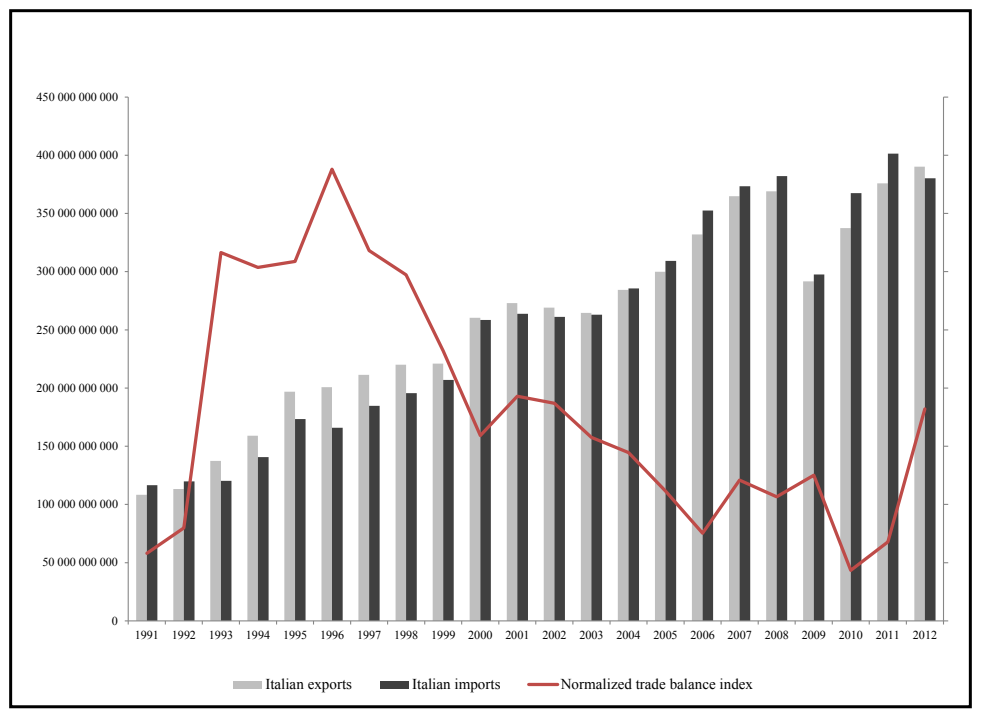

Source: our elaboration on Istat data (2014)

Figure 1: Italy: trade balance trend and relative trade surplus - current values.

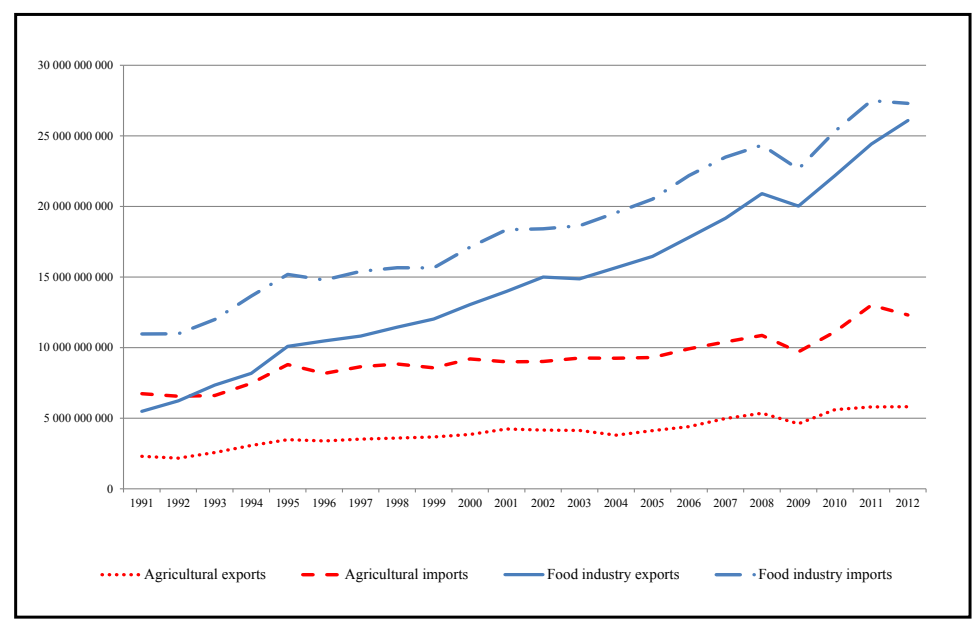

Source: our elaboration on Istat data (2014)

Figure 2: Italy: trend of the agri-food trade balance (1991-2012).

and variety of pedological and climatic environments, which give to agricultural products a unique taste known in all the world. (Platania, Privitera, 2006; Baraldi et al., 2009; Pilato et al., 2015; Rapisarda et al., 2015).

In 2011 and 2012, total agri-food exports accounted for $8 \%$ of the trade balance which had grown from $€ 8 B$ for $1991 / 92$ to $€ 31 B n$ for $2011 / 12$ which exceeded many other manufacturing sectors.

The structural deficit side of the Italian agri-food trade balance is due to two very different internal components: the primary sector which on balance is regularly and structurally negative, and the food industry sector which is in constant growth and represented by those traditional 'Made in Italy' products driving exports in the Italian agrifood sector (figure 2). The dependence on foreign markets is well-known as regards the supply chain to the food derivatives industry which is unable to supply all its own demand from home production (De Devitiis, Maietta, 2013).

If we consider that home food consumption, on a par with other advanced nations, shows a structurally stagnating trend (Alexandratos, 1999; Delgado, 2003), the possibilities of Italian agro-food production development derive from foreign demand, over $80 \%$ of which are in this sector, whereas the internal market is the main destination for fresh agri-food (figure 2).

The agri-food component has different dynamics depending on Region which contribute to a national agri-food balance which is quite diversified. To highlight certain structural aspects of Italy's 
international trade and the various levels of specialisation and dependence of the Regions, the average import and export figures were examined for 2 biennial periods and the trend of the normalised surplus of the Regions (table 1).

It is interesting how the major quotas of national agri-food exchange is concentrated in 4 large northern Regions (Piemonte, Lombardia, Veneto and Emilia Romagna) which on average in the last biennial period contributed to over $60 \%$ of exports and $61 \%$ of imports.

The trend of normalised surpluses during the two biennial periods show totally negative values with few exceptions and an improvement in the second biennial period with positive agri-food performances in Piemonte, Valle d'Aosta, Trentino Alto Adige, Umbria, Abruzzo, Campania and Sicilia.

The objective of this study is to analyse the international specialisation patterns of the Italian Regions.

\section{Materials and methods}

The imports and exports regionals flows for 1991-2011 by economic activity at the two- digit classification level of ATECO (Classification of Economic Activity) 2007 (table 2) will be analysed using Italian National Institute of Statistics (Istat) data (Vicari et al., 2009).

\begin{tabular}{ll}
\hline AA011 & non-perennial crops \\
AA012 & perennial crops \\
AA013 & live plants, bulbs, tubers and roots ect. \\
AA014 & live animals and animal products \\
AA021 & products of forestry \\
AA022 & wood in the rough \\
AA023 & products of wild growing non-wood \\
AA030 & products of fishing and aquaculture \\
CA101 & preserved meat and meat products \\
CA102 & processed and preserved fish, crustaceans and molluscs \\
CA103 & processed and preserved fruit vegetables \\
CA104 & vegetable and animal oils and fats \\
CA105 & dairy products \\
CA106 & grain mill products, starches and starch products \\
CA107 & bakery and farinaceous products \\
CA108 & other food products \\
CA109 & prepared animal feeds \\
CA110 & beverages \\
CA120 & tobacco products \\
\hline
\end{tabular}

Source: ATECO, 2007

Table 2: Italy: trend of the agri-food trade balance (1991-2012).

\begin{tabular}{|c|c|c|c|c|c|c|c|c|}
\hline \multirow{2}{*}{ Regions } & & \multirow{2}{*}{$\begin{array}{c}\text { Resident } \\
\text { population }\end{array}$} & \multicolumn{2}{|c|}{$1991 / 92$} & \multicolumn{2}{|c|}{$2011 / 12$} & \multicolumn{2}{|c|}{ NS } \\
\hline & & & imports & exports & imports & exports & $91 / 92$ & $11 / 12$ \\
\hline \multirow[t]{4}{*}{ North west } & Piemonte & 7.30 & 10.14 & 14.77 & 9.17 & 13.62 & -0.21 & 0.07 \\
\hline & Valle d'Aosta & 0.20 & 0.06 & 0.05 & 0.05 & 0.19 & -0.48 & 0.51 \\
\hline & Lombardia & 16.40 & 24.97 & 13.58 & 23.03 & 15.85 & -0.61 & -0.30 \\
\hline & Liguria & 2.60 & 5.12 & 2.94 & 2.68 & 2.04 & -0.59 & -0.26 \\
\hline \multirow[t]{4}{*}{ North East } & Trentino-A. Adige & 1.70 & 3.23 & 5.82 & 3.56 & 6.02 & -0.10 & 0.13 \\
\hline & Veneto & 8.20 & 10.69 & 9.40 & 13.92 & 14.96 & -0.43 & -0.09 \\
\hline & F.-V.Giulia & 2.00 & 2.13 & 1.69 & 1.86 & 2.23 & -0.47 & -0.03 \\
\hline & Emilia-Romagna & 7.30 & 12.23 & 18.66 & 15.30 & 16.11 & -0.18 & -0.10 \\
\hline \multirow[t]{4}{*}{ Centre } & Toscana & 6.20 & 5.17 & 4.58 & 4.85 & 5.97 & -0.43 & -0.02 \\
\hline & Umbria & 1.50 & 1.03 & 1.48 & 1.04 & 1.49 & -0.21 & 0.05 \\
\hline & Marche & 2.60 & 1.62 & 1.14 & 1.01 & 0.98 & -0.52 & -0.14 \\
\hline & Lazio & 9.30 & 7.05 & 4.00 & 9.28 & 2.44 & -0.59 & -0.66 \\
\hline \multirow[t]{9}{*}{ South } & Abruzzo & 2.20 & 1.18 & 1.09 & 0.94 & 1.55 & -0.41 & 0.12 \\
\hline & Molise & 0.50 & 0.13 & 0.26 & 0.16 & 0.18 & -0.06 & -0.04 \\
\hline & Campania & 9.70 & 5.78 & 7.91 & 5.53 & 8.01 & -0.24 & 0.06 \\
\hline & Puglia & 6.80 & 4.79 & 7.56 & 4.00 & 4.28 & -0.17 & -0.09 \\
\hline & Basilicata & 1.00 & 0.17 & 0.29 & 0.21 & 0.22 & -0.15 & -0.09 \\
\hline & Calabria & 3.30 & 0.95 & 0.54 & 0.60 & 0.45 & -0.59 & -0.27 \\
\hline & Sicilia & 8.40 & 2.62 & 3.42 & 2.05 & 2.95 & -0.26 & 0.05 \\
\hline & Sardegna & 2.70 & 0.93 & 0.83 & 0.75 & 0.46 & -0.43 & -0.36 \\
\hline & & 100.00 & 100.00 & 100.00 & 100.00 & 100.00 & & \\
\hline
\end{tabular}

Source: our elaboration on Istat data (2014)

Table 1: Italy: agri-food balance trend: regional imports and exports (val.\%) and normalised surplus (NS). 
The literature has many indicators of comparative advantage. The Balassa index (1965) of comparative advantage is commonly used and built from the sectorial composition of trade flow for a given period. One of its main drawbacks is that it only relates to exports; degrees of specialization determined from trade flows (exports) alone, may deprive the analysis of significant factors (Boffa et al., 2009). A more comprehensive index with greater explanatory power was proposed by the French economist Lafay (1992). The Lafay index (LFI) is used because of several appealing alternative measures of specialization: it allows for a more precise analysis of the dynamic model descriptors of production specialization (Bugamelli, 2001) than the Balassa index, and can control for intra-industry trade and business cycle variations (Burianova, Belova 2012). Furthermore, in contrast to the Michaely Index (Michaely, 1962) and to the Trade Specialisation Index (Bender and Li, 2002), it can take into account any distortions induced by macro-economic fluctuations (Amable 2000; Caselli, Zaghini, 2005). In this paper, we used a modified version of the LFI taken from Bugamelli (2001). The LFI was compute for the international specialization for the 19 items showed in table 2:

$$
L F I_{j}^{i}=\left(\frac{x_{j}^{i}-m_{j}^{i}}{x_{j}^{i}+m_{j}^{i}}-\frac{\sum_{j=1}^{N}\left(x_{j}^{i}-m_{j}^{i}\right)}{\sum_{j=1}^{N}\left(x_{j}^{i}+m_{j}^{i}\right)}\right) \frac{x_{j}^{i}+m_{j}^{i}}{\sum_{j=1}^{N}\left(x_{j}^{i}+m_{j}^{i}\right)} * 100
$$

where

$x_{j}^{i}=$ exports of region $i$ of a product in economic sector $j$ to the rest of the world;

$m_{j}^{i}=$ imports of a product in economic sector $j$ from the rest of the world to region $i$;

$N=$ is the number of traded goods

According to the above formula, the comparative advantage for region $i$ in the production of economic sector $j$ is the deviation of the product $j$ normalized trade balance from the overall normalized balanced trade (the sum of LFI across $j$ for any year must by design be equal to zero). Positive values of the LFI imply specialization, and higher values of the LFI imply higher degrees of specialization, with the sector making a bigger contribution to the trade balance. Alternately, negative values imply a reliance on imports (Caselli, Zaghini, 2005; Zaghini, 2005; Alessandrini et al., 2007; Platania, 2014). The index considers trade flows for each sector and for the entire sector. It can then establish whether a country is relatively specialized in a given field (in relation to all other economic sectors), even when the country in question is generally a net importer, provided that the percentage difference between imports and exports is lower than the national difference (Boffa et al., 2009).

Using Lafay Index, we want explore the persistence and change in the patterns of international specialization of the Italian regions and whether their degree of international specialization has increased or decreased. A widely-used methodology in international trade data (Zaghini, 2003; Caselli, Zaghini, 2005; Buturac, Teodorović, 2012; Platania, 2014) has been applied. The first step evaluates whether the Italian regions have increased their level of specialization in the agri-food sector by running the following ordinary least squares regression:

$L I_{2011-2012_{i}}=\alpha+\beta L F I_{1991-1992_{i}}+\varepsilon_{i} \quad i=1, \ldots .20$

where LFI 2011-2012 and LFI 1991-1992 are the Lafay indices in the second period (the dependent variable) and first period (the independent variable) of our sample and $i$ represents the 20 italian regions considering in the regression. The variables $\alpha$ and $\beta$ are the standard linear regression parameters and $\varepsilon$ is the residual term. The variables on both sides of the equation have a mean of zero, so the estimate of $\alpha$ should also have a zero value. The value of $\beta$ encompasses the changes over time in the pattern of specialization. If $\beta>1$, the degree to which the Italian regions have specialised (or not) in certain sectors has increased (or decreased). A coefficient $0<\beta<1$ denotes that, on average, specialization has remained the same, even as the Lafay index improved for the items with low initial values and worsened for those with high initial values. If $\beta=0$, then there is no relationship between the pattern of specialization in the two periods.

To evaluate the change in the dispersion of the comparative advantage distribution a second step is needed in which the following equation is applied:

\section{$\frac{V A R \sigma^{\text {end }}}{V A R \sigma^{\text {start }}}=\frac{\beta^{2}}{R^{2}} ;$}

where the numerator and denominator are the variances of the endogenous and exogenous variables, and $R^{2}$ is the coefficient of determination (the square of the correlation coefficient). With this ratio, some data can be provided on the changes in the distribution dispersion of comparative advantages. If $\beta=R$, then the distribution dispersion is unchanged. When $\beta>R$, the degree of specialization increases. Finally, if $\beta<R$, the degree of specialization decreases. As in other 
studies that have used this ratio, $\mathrm{R}$ may be considered as a mobility measure of the products along the distribution. Thus, a high value of $R$ indicates that the relative positions of the individual items have remained almost unchanged, and this indicates that they possess low mobility (Caselli, Zaghini, 2005).

\section{Results and discussion}

Table 3 shows the shape of the overall distribution of the Lafay index. In particular, it shows

\begin{tabular}{|c|c|c|c|c|c|c|}
\hline Area & Regions & $\begin{array}{c}\text { Lafay Index } \\
1991 / 92 \text { sector } \\
\text { with min } \\
\text { and max value }\end{array}$ & $\begin{array}{c}\text { Relative weight } \\
\text { of the top } 5 \text { items } \\
\text { of } 1991 / 92\end{array}$ & $\begin{array}{c}\text { Lafay Index } \\
2011 / 12 \\
\text { sector with min } \\
\text { and max value }\end{array}$ & $\begin{array}{c}\text { Relative weight } \\
\text { of the top } 5 \text { items } \\
\text { of } 2011 / 12\end{array}$ & $\begin{array}{l}\text { Spearman's } \\
\text { correlation } \\
\text { coefficient }\end{array}$ \\
\hline \multirow[t]{8}{*}{ North west } & \multirow{2}{*}{ Piemonte } & AA014 & \multirow{2}{*}{28.69} & AA012 & \multirow{2}{*}{29.23} & \multirow{2}{*}{$.867 * *$} \\
\hline & & CA110 & & CA110 & & \\
\hline & \multirow{2}{*}{ Valle d'Aosta/Vallée d'Aoste } & CA110 & \multirow{2}{*}{20.27} & CA101 & \multirow{2}{*}{22.00} & \multirow{2}{*}{.003} \\
\hline & & AA030 & & CA110 & & \\
\hline & \multirow{2}{*}{ Lombardia } & AA014 & \multirow{2}{*}{9.43} & AA012 & \multirow{2}{*}{13.94} & \multirow{2}{*}{$.867 * *$} \\
\hline & & CA110 & & CA107 & & \\
\hline & \multirow{2}{*}{ Liguria } & AA012 & \multirow{2}{*}{16.31} & CA102 & \multirow{2}{*}{18.53} & \multirow{2}{*}{$.886^{* *}$} \\
\hline & & AA011 & & AA103 & & \\
\hline \multirow[t]{8}{*}{ North-East } & \multirow{2}{*}{ Trentino-Alto Adige/Südtirol } & CA105 & \multirow{2}{*}{34.30} & CA108 & \multirow{2}{*}{27.82} & \multirow{2}{*}{$.625^{* *}$} \\
\hline & & AA012 & & AA012 & & \\
\hline & \multirow{2}{*}{ Veneto } & AA014 & \multirow{2}{*}{21.98} & AA014 & \multirow{2}{*}{22.44} & 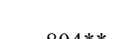 \\
\hline & & CA110 & & CA110 & & $.804 \%$ \\
\hline & 月. & AA022 & 30 & AA012 & $\sim 0$ & \\
\hline & rnuni-venezTa Uiuna & CA107 & 21.13 & CA108 & 25.83 & $.100^{4}$ \\
\hline & 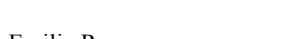 & CA101 & 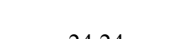 & CA104 & $1-01$ & $701 * *$ \\
\hline & Emina Komagna & AA012 & 24.24 & CA107 & 15.01 & $.191 \%$ \\
\hline Centre & 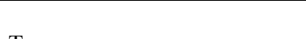 & CA101 & 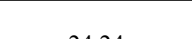 & CA101 & & 100* \\
\hline & Ioscana & CA110 & 24.24 & CA110 & 28.67 & 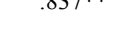 \\
\hline & . & AA014 & 2070 & CA105 & 1074 & $020 * *$ \\
\hline & Unima & AA011 & 50.10 & AA011 & 10.14 & .952 .0 \\
\hline & . & CA120 & 70 & CA120 & & \\
\hline & Laz1o & CA110 & 10.11 & CA108 & 13.44 & $.880^{\circ}$ \\
\hline & M. & AA011 & 1907 & CA102 & 0 & 40 \\
\hline & Mararene & CA104 & 14.07 & CA110 & 29.04 & .449 \\
\hline South & 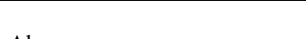 & AA014 & (O) & CA102 & $\Omega$ & \\
\hline & Abruzzo & AA012 & 28.90 & CA107 & 20.84 & . $.010^{*}$ \\
\hline & . & CA105 & 10 & CA105 & 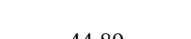 & $027 * *$ \\
\hline & Molise & CA107 & 40.13 & CA107 & 44.89 & $.82 / \%$ \\
\hline & G & AA011 & 3 & AA012 & $\mathrm{SO}_{0}$ & $700 \% *$ \\
\hline & & CA103 & & CA103 & 28.41 & $.159^{\circ}$ \\
\hline & D. & CA104 & 0000 & CA104 & 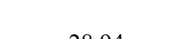 & (020\%* \\
\hline & Pugina & AA012 & 29.38 & AA012 & 28.94 & .939 w \\
\hline & .1. & AA014 & ד & CA104 & 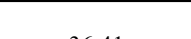 & $70-{ }^{2}$ \\
\hline & Basillicata & $\mathrm{AA} 012$ & 38.97 & AA012 & 36.41 & $.105^{*}$ \\
\hline & Cals. & AA014 & 10 & CA102 & 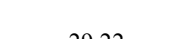 & $027 * *$ \\
\hline & Carabira & CA103 & & CA103 & 29.22 & $.05 / 6$ \\
\hline & $\alpha \cdots \cdot \cdots$ & CA101 & P० & CA101 & PO & $700 \% *$ \\
\hline & Sicilia & AA012 & 29.02 & CA110 & 23.96 & $.700^{2}=$ \\
\hline & & AA011 & & AA011 & & \\
\hline & Sardegna & CA105 & 35.15 & CA105 & 33.35 & $.546^{*}$ \\
\hline
\end{tabular}

Note: * Correlation is significant at the 0.05 level (2-tailed). ${ }^{*}$ Correlation is significant at the 0.01 level (2-tailed). Source: own processing

Table 3: Italian regions: value of the Lafay Index and Spearman's rank correlation coefficient, 1991/92-2011/12 
the economic sectors with the maximum and minimum index values in the two periods of observation (1991-92/2011-12), the weight of the first five items (calculated as sum of the LFI of each item) and Spearman's correlation coefficient. From the table, it may be easily deduced how heterogeneous and variously distributed the territorial specialisations are across Italy. If the weight of the first five sectors in the two surveys is considered then they drop in eight Regions (Trentino Alto Adige, Emilia Romagna, Umbria, Abruzzo, Campania, Puglia, Basilicata and Sicilia).

To analyse this data more deeply, let's look at Spearman's correlation coefficient. In this study, it is able to show the degree of change in the LFI during the two surveys. A high correlation indicates that the region's comparative advantages have changed very little, while a low value indicates considerable change. Eleven Regions show much higher values than this coefficient (close or greater than 0.8). Moreover, excluding cases of little statistical significance, the Regions with a significantly lower Spearman's coefficient (lower than 0.8) are those which showed a lower index in the course of the two surveys. It could be hypothesized that there have been changes in those Regions which have brought about a different way of structuring the weight of trade flow within the agri-food sector.

Finally, it's interesting to look at the specificity of the main specialisations - are they agricultural or perhaps linked to one of the six primary sectors (from sectors AA011 to AA030) or can they be re-traced to food industry (the remaining sectors, table 2). In 1991/92, there are 9 Regions with the highest LFI in a primary sector: 2 in the North-West (Valle d'Aosta, Liguria), 2 in the North-East (Trentino Alto Adige e Emilia Romagna), 1 in the centre (Umbria) and 4 in the South (Abruzzo, Puglia Basilicata e Sicilia). During the second survey this scenario changes. Only 5 Regions retain this competitive advantage (Liguria, Trentino Alto Adige, Umbria, Puglia e Basilicata), no other Region being specialised in a primary which is confirmed by obvious restructuring within much of the Italian agricultural industry.

These first results show the role of transformer that Italy is taking in the international food trade. This corresponds to some of the regions examined, to a model of specialization in which there has been a process of purchase of agricultural raw materials and re-export from the food industry. This is possible for those regions where there is a strong integration with foreign markets and where agriculture interacts in a very dynamic way with the rest of the economy, although with lower connection with the territory.

To look more closely at the characteristics of the foreign trade in agri-food, a further calculation of the Lafay Index was carried out. In particular, the 19 business divisions (see table 2) were unified into 4 groups: agriculture, food industry, beverages and tobacco which resemble the traditional sub-divisions of the sector. Figure 3 shows graphically the index trend during the survey. What's evident is how weak the primary sector is, showing significant de-specialisation over the whole survey period. However, the food industry shows a different trend: apart from in 1994 and 2001, its LFI is always positive. For beverages

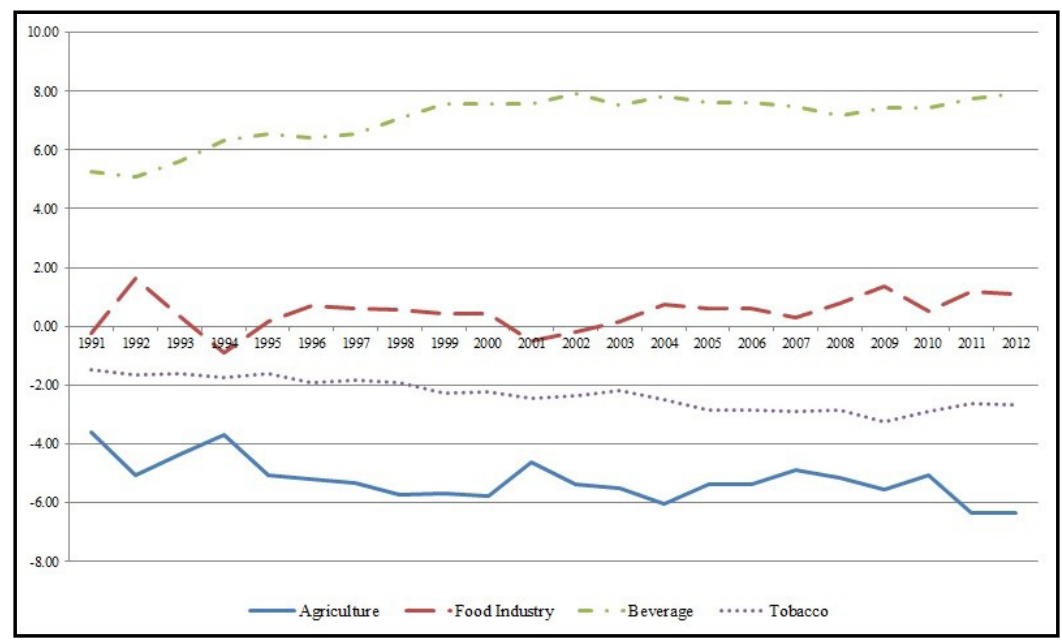

Source: our elaboration on Istat data (2014)

Figure 3: Lafay index of the Italian Agrofood sector. 
too, the Lafay Index remains particularly high and sustained over time.

However, the analysis shown does not provide information on the determinants of a high or low degree of persistence. That is, it does not explain which sectors, in each region, are contributing that persistence or to that change. Therefore, we need further investigation.

\section{The dynamics of international specialization}

Joint analysis of the regression and mobility effects (applying the least squares regression formula) shows the changes in distribution of the comparative advantages over time in the Regions. Table 4 shows the two effects which divide the Regions into three groups.

The specialisation model for the Regions of the first group did not change over the survey period: the $\beta>1$ value shows substantial stability in the specialisation pattern such that growth (or drop) regards sectors in which the Region already showed comparative advantages (or disadvantages), whereas the $\mathrm{B} / \mathrm{R}$ ratio suggests a growth in the level of specialisation. The four Regions (Lombardia, Toscana, Lazio, Molise) are therefore the only ones to have strengthened their levels of specialisation even without modifying their respective models of comparative advantage.

For the Regions in the second group (Piemonte, Valle d'Aosta, Liguria, Veneto, Friuli V. G., Marche, Abruzzo, Calabria, Sardegna), a catch-up model could be hypothesised - a tendency to modify the comparative advantage model (low $R$ ) but by contrast to the first group, with a tendency to grow product specialisation where they were less specialised and to reduce those which were relatively more specialised (low $\beta$ ). These Regions have therefore strengthened their levels of specialisation by modifying their own models of comparative advantage.

Finally, the third group of Regions (Trentino Alto Adige, Emilia Romagna, Umbria, Campania, Puglia, Basilicata, Sicilia) show values of $0<\beta<1$ and $\beta<R$ which means that they have modified their comparative advantage model (as did group 2 ) but in so doing have weakened their own specialisation models.

\section{Conclusions}

This study has examined the processes of persistence and change in the patterns of international agri-food trade in the Italian regions. Joint analysis of the coefficients of determination and mobility have highlighted the degree of specialisation of the Italian Regions over the survey period.

These results confirm many of the observations made in previous studies. Above all, Italy shows comparative advantages in the food industry. The analysis highlights how the Lafay Index is positive over time for beverages (including wines) and food industry. Secondly, there is a regional differentiation in agricultural and agri-industrial specialisation. While the northern Regions are more integrated into European and world markets both in buying raw materials and re-exporting food derivatives (Henke, 2006), the southern Regions are still not very integrated into international markets. So, Italy is divided into two as regards the production, transformation and commercialisation of agri-food products.

Notwithstanding the limited data, this study highlights the role of agricultural and food exports which is often overlooked in analysis and foreign trade policy despite their being runnerup to textile exports and stronger than many other Italian manufacturing industries. It is no wonder that despite the notoriety of Italian food products abroad, there is no corresponding penetration of those markets.

\section{Authors' note:}

This paper was carried out in full collaboration of the authors. "Introduction" is written by Marcella Rizzo; "Materials and methods" is written by Marco Platania and "Results and discussion" by Placido Rapisarda. Conclusion are written together.

\begin{tabular}{|l|l|c|c|}
\hline & \multicolumn{1}{|c|}{$\beta>R$} & $\beta<R$ & $\beta=0$ \\
\hline$\beta=0$ & \multicolumn{1}{|c|}{-} & - & - \\
\hline$\beta>1$ & Lombardia*, Toscana*, Lazio*, Molise* $^{*}$ & & - \\
\hline $0<\beta<1$ & $\begin{array}{l}\text { Piemonte*, Valle d'Aosta***, Liguria*, } \\
\text { Veneto*, Friuli V.G.*, Marche***, } \\
\text { Abruzzo**, Calabria*, Sardegna* }\end{array}$ & $\begin{array}{l}\text { Trentino Alto Adige*, Emilia Romagna*, } \\
\text { Umbria*, Campania*, Puglia*, Basilicata*, } \\
\text { Sicilia* }\end{array}$ & - \\
\hline
\end{tabular}

Note: * Significant at the .01 level, ** Significant at the .05 level, *** Significant at the .1 level Source: own processing

Table 4: Dynamics of international specialization in agro-food sector for Italian regions. 
Corresponding author:

Marco Platania

University of Catania, via della biblioteca 2, Palazzo Ingrassia, 95124 Catania, Italy

E-mail: marco.platania@unict.it

\section{References}

[1] Alessandrini, M., Fattouh, B., Scaramozzino, P. The changing pattern of foreign trade specialization in Indian manufacturing. Oxford Review of Economic Policy. 2007, Vol. 23, No. 2, p. $270-91$. ISSN 1460-2121.

[2] Alexandratos, N. World food and agriculture: outlook for the medium and longer term. Proceedings of the National Academy of Sciences. 1999, Vol. 96, No. 11, p. 5908-5914. ISSN 1091-6490.

[3] Amable, B. International Specialization and Growth. Structural Change and Economic Dynamics. 2000, Vol. 11, No. 4, p. 413-431. ISSN 0954-349X.

[4] Balassa, B. Trade Liberalization and 'Revealed' Comparative Advantage. The Manchester School. 1965, Vol. 33, No. 2, p. 99-123.

[5] Baraldi, F., Canavari, M., Regazzi, D., Spadoni, R. Food and health-contribute of agri-food economics. Italian Journal of Agronomy. 2009, Vol. 4, No. 1, p. 163-170. ISSN 1125-4718.

[6] Bender, S., Li, K. W. The changing trade and revealed comparative advantages of Asian and Latin American manufacture exports. Center discussion paper. Economic Growth Center. 2002, No. 843. [Online] Available: http://hdl.handle.net/10419/39343 [Accessed: Feb. 2015].

[7] Boffa, F., Bolatto, S., Zanetti, G. Specializzazione produttiva e crescita: un'analisi mediante indicatori. CERIS Working Paper. 2009, Vol. 1. ISSN 2036-8216.

[8] Bugamelli, M. Il modello di specializzazione internazionale dell'area dell'euro e dei principali paesi europei: omogeneità e convergenze. Banca d'Italia. 2001, No. 402, p. 7-53. ISSN 1594-7939.

[9] Burianova, J., Belova, A. The competitiveness of agricultural foreign trade commodities of the CR Assessed by way of the Lafay index. Agris on-line Paper in Economics and Informatics. 2012, Vol. 4, No. 4, p. 27-36. ISSN 1804-1930.

[10] Buturac, G., Teodorović, I. The impacts of the global recession on Southeast European Countries. Eastern European Economics. 2012, Vol. 50, No. 1, p. 78-97. ISSN 1557-9298.

[11] Caselli, P., Zaghini, A. International specialization models in Latin America: the case of Argentina. Bank of Italy. 2005, No. 558, p. 6-37. ISSN 1594-7939.

[12] De Devitiis, B., Maietta, O. W. Chapter 8 Regional Patterns of Structural Change in Italian Agriculture, in Ortiz-Miranda D., Moragues-Faus A., Arnalte-Alegre E. (ed.) Agriculture in Mediterranean Europe: Between Old and New Paradigms (Research in Rural Sociology and Development, Vol. 19). Emerald Group Publishing Limited, 2013, p.173 - 205. ISBN 978-1-78190-597-5.

[13] Delgado, C. L. Rising consumption of meat and milk in developing countries has created a new food revolution. The Journal of Nutrition. 2003, Vol. 133, No. 11, p. 3907S-3910S. ISSN 1541-6100.

[14] Henke, R. La specializzazione regionale del commercio agroalimentare italiano. Agriregionieuropa. 2006, Vol. 2, No. 6, p. 34-37. ISSN $1828-5880$.

[15] ISTAT. Coeweb - Statistiche del commercio estero. Rome, 2014. [Online] Avalaible: http://www.coeweb.istat.it/. [Accessed: Jan. 2015].

[16] Lafay, G. The Measurement of Revealed Comparative Advantages, in: Dagenais, M. G., Muet, P. A., (Eds.), International Trade Modeling, London. Chapman and Hill, 1992. ISBN 9780412450006.

[17] Michaely, M. Concentration in international trade. Amsterdam: North-Holland, 1962. 
[18] Pilato, M., Platania, M., Rizzo, M. The value of country of origin in the consumption. Results of a survey on sicilian products. Quality - Access to Success. 2015, Vol. 16, No. S1, p. 150-157. ISSN 1582-2559.

[19] Platania, M. Agglomerazione industriale, integrazione verticale e specializzazione produttiva. Verifiche empiriche delle ipotesi marshalliane. l'Industria. Rivista di economia e politica industriale. 2012, Vol. 33, No. 2, p. 305-25. ISSN 0019-7416.

[20] Platania, M. Trade Advantage Of Italian Industrial Districts: Persistence And Change. Regional and Sectoral Economic Studies. RSES. 2014, Vol. 14, No. 2, p. 39-52. ISSN 1578-4460.

[21] Platania, M., Privitera, D. Typical products and consumer preferences: The "soppressata" case. British Food Journal. 2006, Vol. 108, No. 5, p. 385-395. ISSN 0007-070X.

[22] Rapisarda, P., Rizzo M., Scuderi A. Analysis of a direct selling network for agrifood products. Italian Journal of Food Science. 2015, Vol. 27, No. 1, p.109-117. ISSN 1120-1770.

[23] Vicari P., Ferrillo A., Valery A. (eds). Classificazione delle attività economiche - Ateco 2007. Metodi e norme n. 40. Roma: Istat, 2009. ISBN 978-88-458-1614-7.

[24] Zaghini, A. Trade Advantages and Specialization Dynamics in Accession Countries. European Central Bank. 2003, Working Paper 249. ISSN 1725-2806.

[25] Zaghini, A. Evolution of trade patterns in the new EU member states. Economics of transition. 2005, Vol. 13, No. 4, p. 629-658. ISSN 1468-0351. 